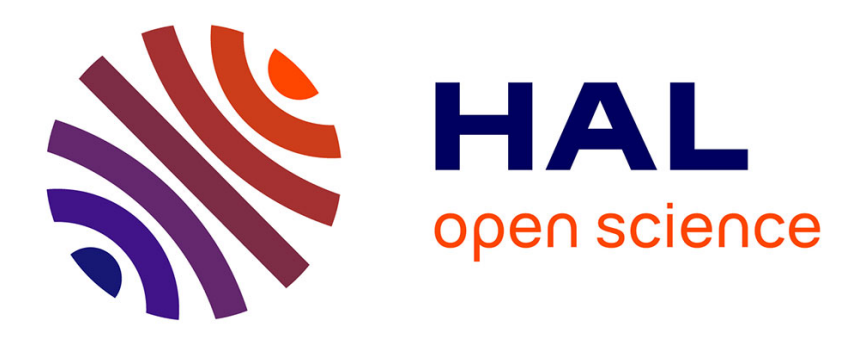

\title{
Katabatic jumps in the Martian northern polar regions
} Aymeric Spiga, Isaac Smith

\section{To cite this version:}

Aymeric Spiga, Isaac Smith. Katabatic jumps in the Martian northern polar regions. Icarus, In press, 10.1016/j.icarus.2017.10.021 . hal-01643458

\section{HAL Id: hal-01643458 https: / hal.sorbonne-universite.fr/hal-01643458}

Submitted on 21 Nov 2017

HAL is a multi-disciplinary open access archive for the deposit and dissemination of scientific research documents, whether they are published or not. The documents may come from teaching and research institutions in France or abroad, or from public or private research centers.
L'archive ouverte pluridisciplinaire HAL, est destinée au dépôt et à la diffusion de documents scientifiques de niveau recherche, publiés ou non, émanant des établissements d'enseignement et de recherche français ou étrangers, des laboratoires publics ou privés. 


\title{
Katabatic jumps in the Martian northern polar regions
}

\author{
Aymeric Spiga*1 and Isaac Smith ${ }^{2}$ \\ ${ }^{1}$ Laboratoire de Météorologie Dynamique / Institut Pierre-Simon Laplace (LMD/IPSL), Sorbonne Universités, \\ UPMC Univ Paris 06, PSL Research University, École Normale Supérieure, Université Paris-Saclay, École \\ Polytechnique, Centre National de la Recherche Scientifique, France \\ ${ }^{2}$ Planetary Science Institute, Denver, Colorado, USA
}

October 2, 2017

${ }^{*}$ Corresponding author: aymeric.spiga@upmc.fr 


\section{Abstract}

2 Martian polar regions host active regional wind circulations, such as the downslope katabatic winds

3 which develop owing to near-surface radiative cooling and sloped topography. Many observations

4 (stratigraphy from radar profiling, frost streaks, spectral analysis of ices) concur to show that aeolian

5 processes play a key role in glacial processes in Martian polar regions. A spectacular manifestation

6 of this resides in elongated clouds that forms within the polar spiral troughs, a series of geological

7 depressions in Mars' polar caps. Here we report mesoscale atmospheric modeling in Martian

\& polar regions making use of five nested domains operating a model downscaling from horizontal

9 resolutions of twenty kilometers to 200 meters in a typical polar trough. We show that strong

${ }_{10}$ katabatic jumps form at the bottom of polar troughs with an horizontal morphology and location

11 similar to trough clouds, large vertical velocity (up to $+3 \mathrm{~m} / \mathrm{s}$ ) and temperature perturbations

12 (up to $20 \mathrm{~K}$ ) propitious to cloud formation. This strongly suggests that trough clouds on Mars

13 are caused by katabatic jumps forming within polar troughs. This phenomena is analogous to

14 the terrestrial Loewe phenomena over Antarctica's slopes and coastlines, resulting in a distinctive

15 "wall of snow" during katabatic events. Our mesoscale modeling results thereby suggest that trough

${ }_{16}$ clouds might be present manifestations of the ice migration processes that yielded the internal cap

17 structure discovered by radar observations, as part of a "cyclic step" process. This has important

${ }_{18}$ implications for the stability and possible migration over geological timescales of water ice surface

19 reservoirs - and, overall, for the evolution of Mars' polar caps over geological timescales.

\section{${ }_{20} 1$ Introduction}

${ }_{21}$ Studying the meteorology of the Martian polar regions is a means to address key questions related 22 to the Martian climate from the global to the local scales. Planetary-scale "flushing" storms originate from the Martian polar regions and transport dust particles in lower latitudes, thereby 24 impacting the global climate of Mars (Cantor et al., 2002; Toigo et al., 2002). Modeling studies to 
prepare the landing of the Phoenix polar lander (Kauhanen et al., 2008; Tyler et al., 2008; , Michaels and Rafkin, 2008) detailed how the atmospheric variability in the Martian northern polar regions is controlled by a combination of the mean meridional circulation (Wilson, 1997; Forget et al., 1999) responsible for the characteristic polar warming in Mars' lower mesosphere (McCleese et al., 2008), the circumpolar jet (Toigo et al., 2012; Mitchell et al., 2015; Guzewich et al., 2016), baroclinic waves (Barnes et al., 1993; Collins et al., 1996), and regional circulations (Toigo et al., 2002, Tyler and Barnes, 2005). The variability of regional (so-called mesoscale) circulations in the polar regions is also a matter of active research to disentangle the combined influence of slope acceleration (Spiga et al., 2011; Smith et al., 2013), "sea-breeze" circulations caused by the direct cap-edge thermal contrasts (Toigo et al., 2002, Smith et al., 2015), and polar transient eddies (Tyler and Barnes, 2005). Understanding the interplay of global and mesoscale circulations in the Martian polar regions is of primary importance to characterize the seasonal source / sink those regions represent for Mars' water cycle (Tyler and Barnes, 2014, Navarro et al., 2014).

Katabatic winds are a salient component of the atmospheric variability in Martian polar regions, just as they are on the Earth (Parish and Waight, 1987; Gallée and Schayes, 1992, Bromwich et al., 2001; Nylen et al., 2004). Katabatic winds are drainage atmospheric flows that form when cooled dense air is accelerated down sloping terrains by gravity, overcoming the opposing alongslope pressure gradient (Mahrt, 1982). The combination of sloping terrains, near-surface radiative cooling, and surface ice cover (either $\mathrm{CO}_{2}$ ice in winter or $\mathrm{H}_{2} \mathrm{O}$ deposits apparent in spring), makes the Martian polar regions particularly prone to the development of katabatic winds over an extended period of time (Spiga, 2011; Smith et al., 2015). This is evidenced by numerous surface morphologic features in the northern polar regions, from frost streaks to dune fields, thought to be caused by the polar katabatic flow deflected by the Coriolis force (Massé et al., 2012). The variability of spectral signatures $\left(\mathrm{H}_{2} \mathrm{O}\right.$ or $\left.\mathrm{CO}_{2}\right)$ over the polar slopes during the seasonal retreat have been plausibly ascribed to katabatic winds too (Appéré et al., 2011), as well as small-scale sedimentation undulations over the northern polar plateau (Herny et al., 2014). The formation of 
geological structures through time has also been possibly linked to the action of katabatic winds (e.g., Abalos Mensae, Brothers et al., 2013). The impact of katabatic winds on polar geological features is not only aeolian, but also thermal: especially above steep slopes, they induce a significant downward sensible heat flux which acts either to warm the surface or to increase sublimation rates (Spiga et al., 2011).

Radar stratigraphic observations of the Martian polar caps strongly suggest polar wind circulations, especially katabatic winds, have been instrumental in shaping the northern polar cap, and the related northern polar layered deposits, over geological timescales (Holt et al., 2010; Smith and Holt, 2010; Smith and Holt, 2015). Radar measurements renewed the interest for the idea that katabatic winds, deflected by the Coriolis force, may explain the spiral organization of the polar troughs, the deep depressions $(400-1000 \mathrm{~m})$ incised in the northern polar cap of Mars (Howard et al. 1982: Howard, 2000; Pathare and Paige, 2005). This idea has been pushed forward by Smith et al. (2013) who combined radar measurements, visible imaging, and numerical modeling, to show that 1 . the layering below troughs evidenced by radar stratigraphy supports a migration of trough in the upslope direction as part of a "cyclic step" process (Kostic et al., 2010); 2. the fluid current associated with this "cyclic step" mechanism is the katabatic wind flow where the occurrence of "hydraulic jumps" enables ice migration to occur from the upstream to the downstream part of the trough; 3. ice migration process could be observed directly in the form of elongated "trough clouds" (Figure 1) occurring at the bottom of the northern polar troughs in early summer. This scenario has been extended to the southern polar cap of Mars (Smith et al., 2015), with the additional result that "sea-breeze" circulations caused by the receding seasonal $\mathrm{CO}_{2}$ cap modulate the intensity of katabatic winds and account for the poleward progression of clouds in southern polar regions.

The arguments developed by Smith et al. (2013) on hydraulic jumps within Martian polar katabatic flows (what is named hereafter "katabatic jumps", see diagram in Figure2) only relied on simple analogy with the terrestrial elongated "wall-of-snow" that results from katabatic jumps over 


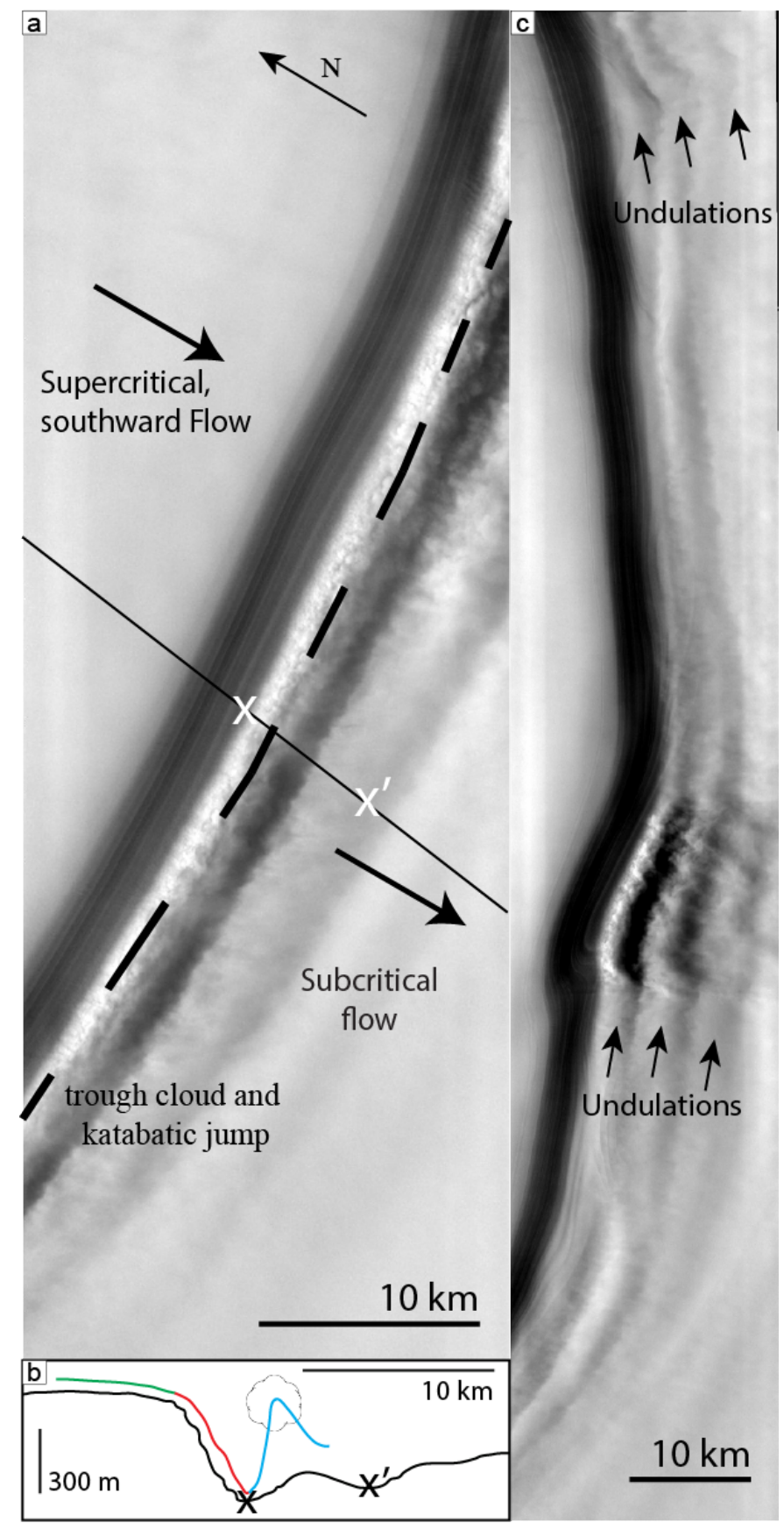

Figure 1: Annotated Mars Odyssey THEMIS images of trough clouds (see Smith et al. (2013) for details on those images). Left image (reference V28743004) shows a distinctive elongated cloud with additional undulations downstream. This image has been obtained in the same trough as the one simulated in domain \#5 (see Figure 7). Right image (reference V28744006) shows a similar phenomena, albeit with smaller extent, in a neighboring trough. 
e.g. Antarctica slopes and coastlines (Lied, 1964; Pettré and André, 1991). What is alternatively named the Loewe phenomenon has been reproduced in simulations of the katabatic flow in the vicinity of coastal slopes in the terrestrial polar caps (Gallée and Schayes, 1992; Pettré et al., 1993; Gallée et al., 1996; Yu and Cai, 2006). It remains to be demonstrated that katabatic jumps do occur in the environmental conditions of the Martian polar regions - and what the characteristics of these katabatic jumps are. It also remains to be elucidated how katabatic jumps cause the elongated clouds observed in Martian polar troughs.

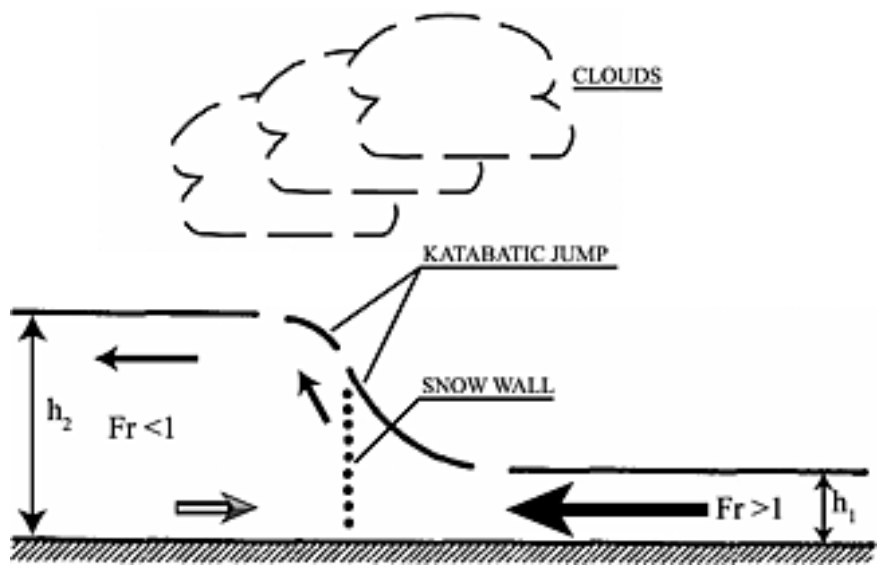

Figure 2: Cartoon depiction of katabatic jump in Antarctica - reproduced with permission from Pettré and André (1991). Arrows indicate atmospheric flow directions. Right to left, the incoming flow, resulting e.g. from katabatic acceleration along a slope, is supercritical ("shooting" flow, according to the terminology in Ball, 1956). Flow depth increases at the katabatic jump. Ice forms at snowline (wall of snow), and clouds form at site of katabatic jump. Downstream of the katabatic jump, flow is subcritical ("tranquil" flow), with a return flow close to the surface in opposite direction than the incoming flow.

In this paper, we propose to address those open questions with mesoscale numerical modeling of the Martian atmosphere. Mesoscale modeling aims at resolving the vast and diverse population of phenomena of smaller extent than a few hundreds of kilometers - in other words, the plethora of atmospheric phenomena left unresolved by Global Climate Models [GCM] (Wilson, 1997; Forget et al., 1999; Navarro et al., 2014). The technique of mesoscale modeling has been employed to obtain many of the aforementioned results on the Martian polar meteorology, especially on the 
regional scale (Toigo et al., 2002, Tyler and Barnes, 2005; Kauhanen et al., 2008; Tyler et al., 2008; Michaels and Rafkin, 2008; Spiga et al., 2011; Smith et al., 2013; Tyler and Barnes, 2014; Smith et al., 2015). Mesoscale models are well-suited to get insights into atmospheric and surface processes in polar regions. Contrary to GCMs, mesoscale models integrate the atmospheric dynamics at high resolution in a specific region of interest on the planet with an adapted map projection. Polar mesoscale domains are defined through stereographic projections, hence devoid of the "pole singularity" present in many GCMs. In addition, high-resolution surface topographical and thermophysical properties (albedo, thermal inertia, $\mathrm{CO}_{2}$ ground ice cover) are used in mesoscale modeling.

Section 2 contains a technical description of the novel mesoscale simulations we carried out to address the formation of katabatic jumps in Martian polar troughs. Section 3 comprises a description of the results we obtained with those simulations and a discussion of the properties of the simulated katabatic jumps - including an exploration of the analogy with terrestrial phenomena, and the possibility for cloud formation within those katabatic jumps. Section 4 contains a summary of both our conclusions and the perspectives our work opens for future studies.

The companion paper Smith and Spiga (2017) addresses the variability of regional winds over the northern polar cap; this paper addresses the behavior of the atmospheric flow at the local trough level. The two companion papers complement one another and can be consulted independently.

\section{Model}

This study is based on simulations performed with the "Laboratoire de Météorologie Dynamique" (LMD) Martian Mesoscale Model (MMM) (Spiga and Forget, 2009; Spiga et al., 2011). Details about the LMD-MMM and typical test simulations can be found in Spiga and Forget (2009). The hydrodynamical solver (dynamical core) of the LMD-MMM is borrowed from the threedimensional, fully compressible, non-hydrostatic Weather Research and Forecasting (WRF) model, 
capable to resolve fine-scale circulations on the Earth (Skamarock and Klemp, 2008). The physical parameterizations for the phenomena left unresolved by the dynamical core (radiative transfer, small-scale mixing) in the LMD-MMM are similar to those developed for the LMD Martian GCM (MGCM) (Forget et al., 1999). Turbulent vertical diffusion (small-scale mixing) is parameterized by a "2.5-order" Mellor and Yamada approach (Mellor and Yamada, 1982), including improvements from Galperin et al. (1988), suitable for the Martian atmosphere prone to strong variability in atmospheric stability in the near-surface; horizontal diffusion is handled by the built-in ARW-WRF scheme based on horizontal deformation (Smagorinsky, 1963). The transport of water tracers and the formation of clouds are not activated in our nested mesoscale simulations, for it significantly raises the computational cost of those (already expensive) simulations. Moreover, reproducing the water vapor and ice fields in the northern polar regions is a notoriously difficult task (Tyler and Barnes, 2014), which is far beyond the scope of the present paper.

The LMD-MMM and LMD-MGCM simulations performed in this paper do not include the recent improvements of the physical parameterizations developed at LMD, namely the interactive dust scheme (Spiga et al., 2013), the radiative transfer of water-ice clouds (Madeleine et al., 2012), and the thermal plume model for boundary-layer turbulence (Colaïtis et al., 2013). We rely instead on a less up-to-date version of the LMD-MMM (Spiga and Forget, 2009; Spiga et al., 2011), akin to the one used in Smith et al. (2013) and similar to the published polar mesoscale models (Kauhanen et al., 2008; Michaels and Rafkin, 2008; Tyler and Barnes, 2014), which proved to satisfyingly reproduce the near-surface wind directions observed by frost-streak mapping (Massé et al., 2012). The reproduction of this wind regime above the northern polar cap is an essential basis of the present work, which focuses on local-scale phenomena arising within the regional katabatic flow over the cap. The interactions in polar regions between water-ice clouds and regional circulations through the radiative impact by water-ice particles remain to be investigated in future work.

The mesoscale domains employed for polar simulations are centered on the northern pole of Mars and make use of polar stereographic map projection. To downscale our mesoscale simulation 

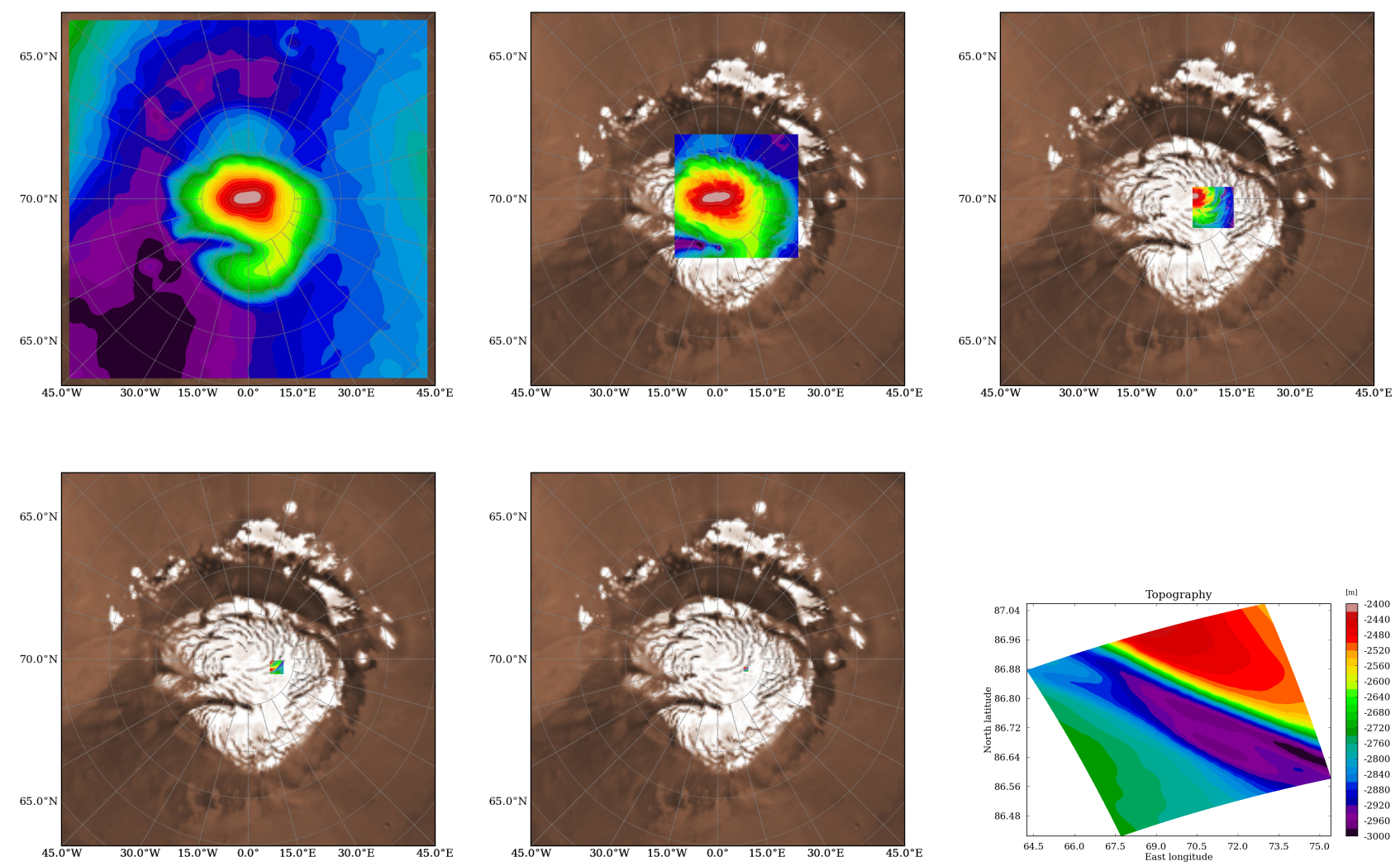

Figure 3: The five nested LMD-MMM domains set for northern polar trough simulations (\#1-5 from left to right and top to bottom). These horizontal domains comprise $121 \times 121$ horizontal grid points with grid spacing being $20 \mathrm{~km}$ (domain \#1 "mother domain"), $6.7 \mathrm{~km}$ (domain \#2), $2.2 \mathrm{~km}$ (domain \#3), $740 \mathrm{~m}$ (domain \#4), $250 \mathrm{~m}$ (domain \#5). Color shading shows topography and the extent of the LMD-MMM domains. An albedo map of the Martian northern polar region is included in the background to provide context. The bottom-right panel shows the detailed topography of the fifth nest located within a single northern polar trough with an fine horizontal resolution of $250 \mathrm{~m}$.

from the complete extent of the Martian northern polar cap (about $15^{\circ}$ latitude wide) towards a single polar trough (about $10-25 \mathrm{~km}$ wide, with a characteristic spacing over the polar cap of 20-70 km, cf. Howard (2000); Pathare and Paige (2005); Smith et al. (2013)), we use 5 "nested" $6.7 \mathrm{~km}, 2.2 \mathrm{~km}, 740 \mathrm{~m}, 250 \mathrm{~m}$ (the factor 3 in grid nesting is the one recommended for most terrestrial applications with the WRF model). The location and extent of the mesoscale nested domains are shown in stereographic projection in Figure 3. The nested domains \#1, \#2, \#3 are 
identical to the mesoscale simulations presented in Smith et al. (2013) (cf. Figure 14) and Smith and Spiga (2017); the present study adds the two unprecedented fine-resolution nested domains \#4 and \#5 to resolve atmospheric winds within a polar trough. Note that the mother domain „\#1 is not wide enough to capture the variability imposed by polar transients evidenced in Tyler and Barnes (2005); here we emphasize the major properties of katabatic jump events on Mars, and their variability over two to three days, but our simulations are not tailored to investigate any longer-duration transient effects, which is left as future work.

The meteorological fields in nested domain $\# n$ are impacted by those predicted in the wider domain $\# n-1$. This configuration is named "one-way nesting"; the possibility of "two-way nesting" (predictions in domain \#n also influencing back predictions in wider domain $\# n-1$ ) does exist in the WRF model, but is not activated here since we do not aim to study the impact of small-scale circulations on the large-scale flow. Initial and boundary conditions for the domain \#1 in the LMD-MMM are provided by LMD-MGCM simulations (Forget et al., 1999) which use similar physical parameterizations, thereby reducing inconsistencies in physics. The WRF dynamical core can be employed either with or without the hydrostatic assumption: in the first three nested domains \#1, \#2, \#3 hydrostatic equilibrium is assumed, while non-hydrostatic integrations are performed in the two higher-resolution nested domains \#4 and \#5 where strong local vertical acceleration (namely, katabatic jumps) are expected to be resolved. LMD-MMM integrations are carried out with timesteps of $60 \mathrm{~s}, 30 \mathrm{~s}, 10 \mathrm{~s}, 3 \mathrm{~s}, 1 \mathrm{~s}$ in the respective nested domains; radiative transfer computations are performed every $300 \mathrm{~s}$ (about 1/12th of a Martian hour) in all 5 nested domains

The topography resolved in the latest (fifth) nest is also shown in Figure 3 to illustrate how our mesoscale simulations is unprecedented in that it resolves the atmospheric flow at high horizontal resolution within a given polar trough. The resolution used in this latest nest is akin to the kind of resolution used in turbulence-resolving Large Eddy Simulations employed to study the daytime convective boundary layer (Rafkin et al., 2001; Michaels and Rafkin, 2004; Tyler et al., 2008; Spiga 
et al., 2010). Both the resolutions of the fourth $(740 \mathrm{~m})$ and fifth $(250 \mathrm{~m})$ nests are within the "grey zone" (or "Terra Incognitae", Wyngaard, 2004) for resolved / parameterized convection: this is not, however, an issue here since our modeling domains are located at polar latitudes where the Martian atmosphere is characterized by high stability and the daytime boundary-layer convection is weak, if not absent.

Along the vertical dimension (Figure 4), 61 levels are set from the surface to a pressure level of about $1 \mathrm{~Pa}$ (about $60 \mathrm{~km}$ ), with a refined spacing close to the surface (first level at an altitude of $8 \mathrm{~m}$ above the surface and 10 levels for the first kilometer above the surface), suitable to study the strong near-surface gradients of temperature and winds putatively occurring in katabatic jumps. We carried out simulations with a distinct, alternate, refinement of the vertical grid close to the surface which yield very similar (i.e., almost identical) results to the ones obtained with the vertical grid shown in Figure 4 .

Our 5-nest mesoscale simulations are carried out close to northern summer solstice $\left(L_{s}=85^{\circ}\right)$ which is a season propitious to the occurrence of trough clouds according to Smith et al. (2013) (in the companion paper, Smith and Spiga (2017) discuss the possible reasons for this strong seasonal trend). The outputs from LMD-MGCM simulations at this season are directly used as initial and boundary conditions for domain \#1: no modification are introduced to enhance the likelihood of katabatic jump occurrences in our LMD-MMM simulations. The LMD-MMM simulations are carried out for 3 Martian days, with the first day serving as a spin-up for the mesoscale circulations (Rafkin et al., 2001; Spiga and Forget, 2009). The dust scenario used in the LMD-MMM simulations is derived from Thermal Emission Spectrometer observations for Martian Year 24 (typical of any Martian Year devoid of global dust storms) and interpolated using a kriging technique (Montabone et al., 2015). Topography in the 5 mesoscale domains is interpolated from the 64-pixel-per-degree laser altimetry (MOLA) dataset (Smith et al., 2001) available on the NASA Planetary Data System. We use the surface thermophysical properties (albedo and thermal inertia) tailored for the northern polar regions published and carefully validated in Tyler and Barnes (2014). 

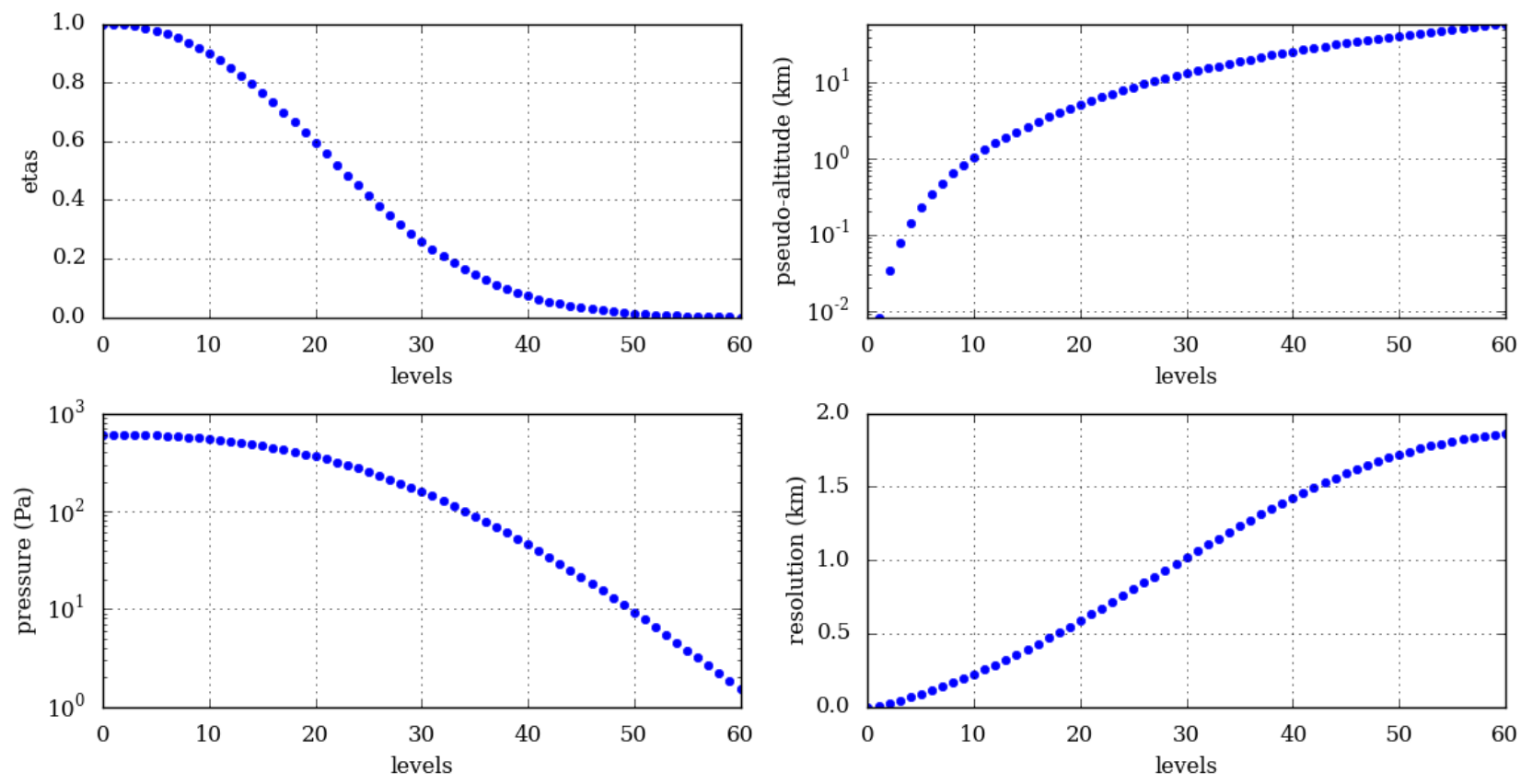

Figure 4: Vertical discretization in the LMD-MMM domains. Pressure at the top of the mesoscale domains is $1 \mathrm{~Pa}$. $x$ axis denotes model vertical levels. y axis corresponds respectively to (top-left panel) WRF terrain-following mass-based coordinates $\left(\eta=\left(p-p_{t}\right) /\left(p_{s}-p_{t}\right)\right.$, where $p$ denotes here the hydrostatic component of pressure, and the $t$ and $s$ subscript denotes respectively the top and surface boundaries), (top-right panel) altitude in $\mathrm{km}$, (bottom-left panel) pressure in Pa, (bottomright panel) vertical resolution in $\mathrm{km}$. Indicative values shown here are computed with standard surface pressure $610 \mathrm{~Pa}$ and scale height $10 \mathrm{~km}$; the actual model top in simulations is at $\sim 57 \mathrm{~km}$ altitude.

Similarly to what is described in Smith et al. (2015), and in the companion paper Smith and Spiga (2017), we use in our LMD-MMM simulations a prescribed CO2 seasonal deposit that evolves by $L_{s}$ date according to infrared measurements of the surface temperature during three typical Mars years (Titus, 2005), using analytical functions to obtain the "crocus line" i.e. the external boundary of seasonal CO2 ice deposits (Kieffer et al., 2000). This accounts for the influence of the ice-soil thermal contrasts in driving near-surface winds in an analogous phenomenon as "seabreeze" on the Earth (Siili et al., 1999; Toigo et al., 2002). Outside the seasonal CO2 deposits, surface temperature is calculated in our model by a surface energy balance model (as in Spiga and Forget, 2009). 


\section{Results}

Results obtained in the domains 1 to 3 with the LMD-MMM are in line with results previously published in Massé et al. (2012) and Smith et al. (2013). A typical near-surface wind field obtained in domain \#2 is shown in Figure 5. These wind circulations over the northern polar cap are mostly controlled by katabatic acceleration and Coriolis force, with wind directions in agreement with those obtained by frost streak mapping (Howard, 2000; Massé et al., 2012) and other mesoscale models (Tyler and Barnes, 2005; Kauhanen et al., 2008). Model results in domain \#3 show that polar troughs cause a local reinforcement of katabatic winds above the steepening slope on the upstream part of the trough, before katabatic winds are severely weakened downstream, within the bottom of the trough (similar to Figure 14 in Smith et al., 2013). Katabatic winds undergo a diurnal cycle and day-to-day variability under the influence of varying regional atmospheric conditions. The full variability imposed by polar transient eddies described in Tyler and Barnes (2005) is not represented in our mesoscale simulations since we ran our mesoscale model for much less than the 25 simulated days required for those transients to develop and propagate through the model. While this does not jeopardize the main results discussed here, the longer-duration (i.e., weekly) variability of the resolved atmospheric phenomena is not captured by our simulations, which will require a dedicated study in the future to explain why trough clouds did not persist throughout northern summer (Smith et al., 2013; Smith and Spiga, 2017).

Analyzing the results from the LMD-MMM in domain \#5 (horizontal resolution $250 \mathrm{~m}$ ) demonstrates that katabatic jumps take place within troughs in the Martian northern polar regions. This is evidenced by Figure 6 where potential temperature is displayed, with wind vectors superimposed, for the second day of simulation at local time 1730 (i.e. 31 hours after the mesoscale simulation was started). Potential temperature is temperature corrected for the impact of adiabatic compression / depression on the temperature (see e.g. Holton, 2004), meaning that potential temperature is conserved for adiabatic motions and represents material contours for the flow. $h$ is the thickness of the katabatic layer, calculated as the distance between the surface and a reference potential 


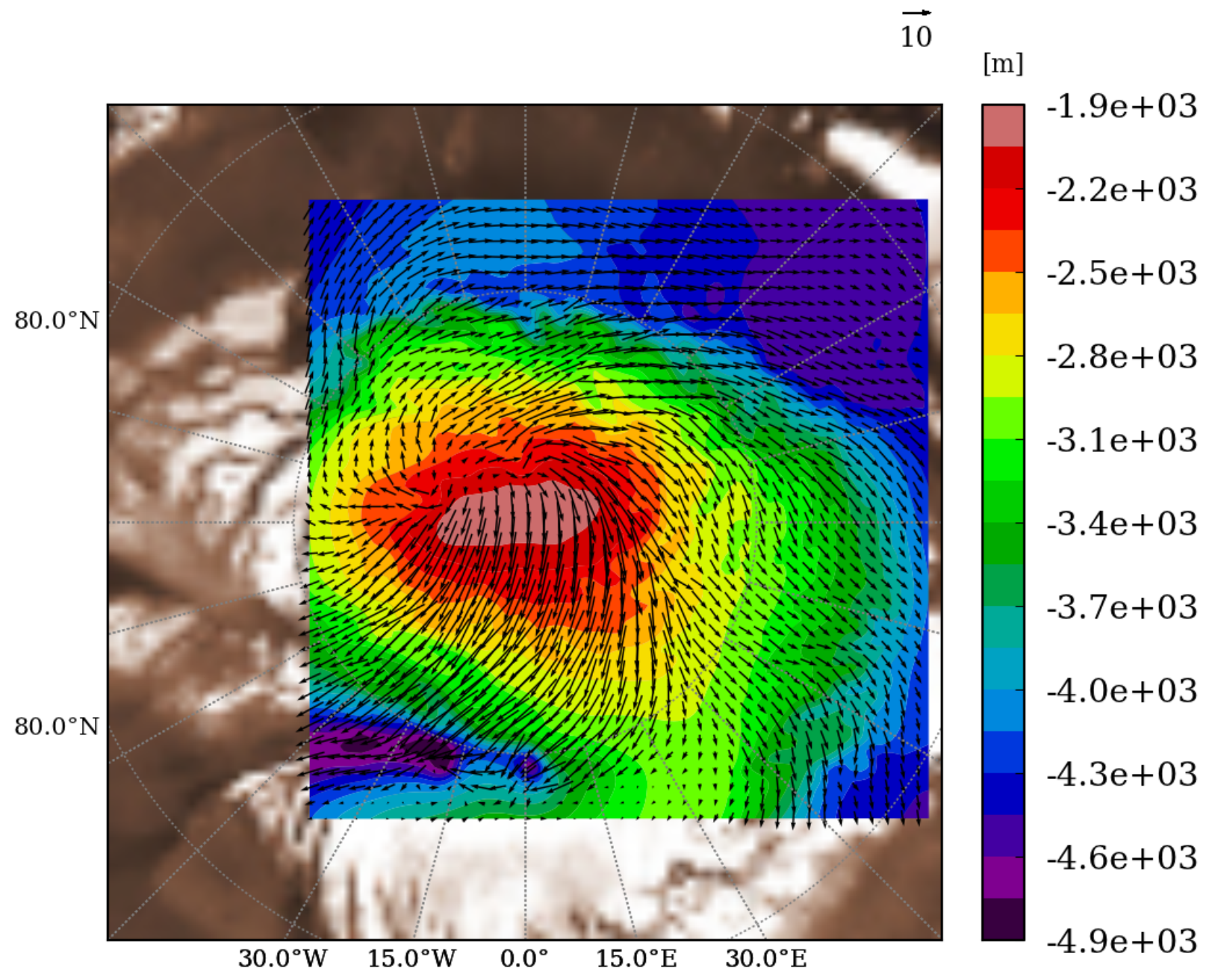

Figure 5: $\quad$ LMD-MMM results in nested domain \#2 $(\Delta x=6.7 \mathrm{~km})$. Horizontal wind vectors $50 \mathrm{~m}$ above the local surface (the reference wind vector with a value in $\mathrm{m} \mathrm{s}^{-1}$ is included in the top right side of the plot). Topography is in shaded colors. An albedo map of the Martian northern polar region is included in the background to provide context. 


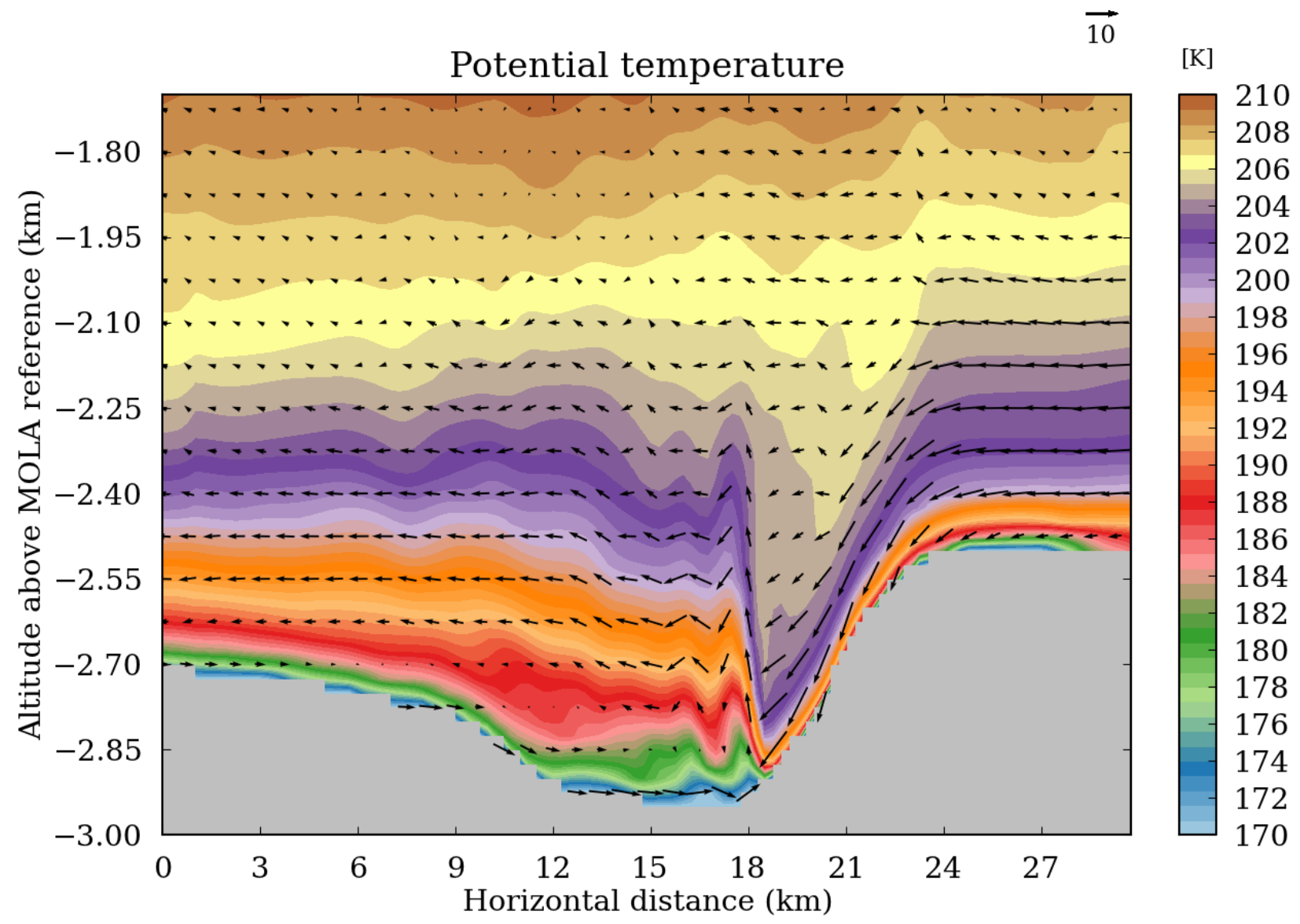

Figure 6: LMD-MMM results in nested domain \#5 $(\Delta x=250 \mathrm{~m})$. Horizontal-vertical crosssection of potential temperature with wind vectors superimposed (the reference wind vector with a value in $\mathrm{m} \mathrm{s}^{-1}$ is included in the top right side of the plot). Vectors plotted every three grid points. This cross-section in the south-north direction (north is on the rightside) is extracted in the middle of domain \#5 in the west-east direction. Figure 8 complements this figure by providing a detailed view on horizontal velocities and temperature.

temperature level of $202 \mathrm{~K}$ (this value of potential temperature is chosen to enclose the nearsurface atmospheric layers where the incoming katabatic wind velocity is high). Figure 6 shows as described in the terrestrial literature and summarized in Figure 2; acceleration of the atmospheric flow on the slope, intense jump diagnosed by abruptly increasing vertical velocity and flow thickness, and return flow with negative horizontal velocity. Katabatic jumps simulated by our 
mesoscale model extends over a height $h \sim 600 \mathrm{~m}$ (cf. also Figure 7 bottom-right panel) and develop mostly at the bottom of the upstream slope of the polar trough, exactly where trough clouds are observed to form (Figure 11). Katabatic jumps are also resolved in domain \#4 but both the topographic structure of the trough and the horizontal extent of the katabatic jump are insufficiently resolved in this domain, which makes the inclusion of domain \#5 necessary to fully resolve the structure with an appropriate horizontal resolution.

Figures 7, 8, 9 represent the properties of the katabatic jump (vertical velocity, horizontal velocity, temperature) respectively in the horizontal, in the vertical, and profiling the flow at constant height above the surface. Our mesoscale model predicts that the vertical wind velocity is very large in the katabatic jump. Ascending motions within the katabatic jump reach $3 \mathrm{~m} \mathrm{~s}^{-1}$ (Figure 8 and 9, top panels) and maintain at those high values during $\sim 10$ Martian hours. This is a significantly high value in a polar environment where the atmosphere is often stable and devoid of strong vertical motions. The large, positive values of vertical velocity in Figures 7, 8, 9 delimit horizontally the katabatic jump to less than $1 \mathrm{~km}$ across (about $4-5$ horizontal grid points, which justifies a posteriori the need to use a modeling downscaling towards a $250 \mathrm{~m}$ horizontal resolution). The elongated structure of the katabatic jump in Figure 7 (top-left panel) mirrors the elongated structure of trough cloud evidenced through orbital imagery by Smith et al. (2013) (Figure 7 thereby confirms that two-dimensional sections such as Figures 6, 8, 9 are valuable to obtain the properties of the katabatic jump). Furthermore, the presence of trapped gravity waves in the wake of the katabatic jump (cf. vertical velocity as vectors in Figure 6 and contours in Figures 7 and 8) provides an explanation for the frequent occurrence of undulations in the morphologies of the trough clouds evidenced through imagery (see Figure 1 in this paper and Figure 3-5 in Smith et al., 2013).

The season chosen for our 5-nest mesoscale simulation is $L_{s} \sim 85^{\circ}$, known as the peak season for trough clouds (Smith et al. 2013). Smith and Spiga (2017) show through mesoscale modeling that this season is propitious to strong katabatic winds over the northern polar cap, reinforced 

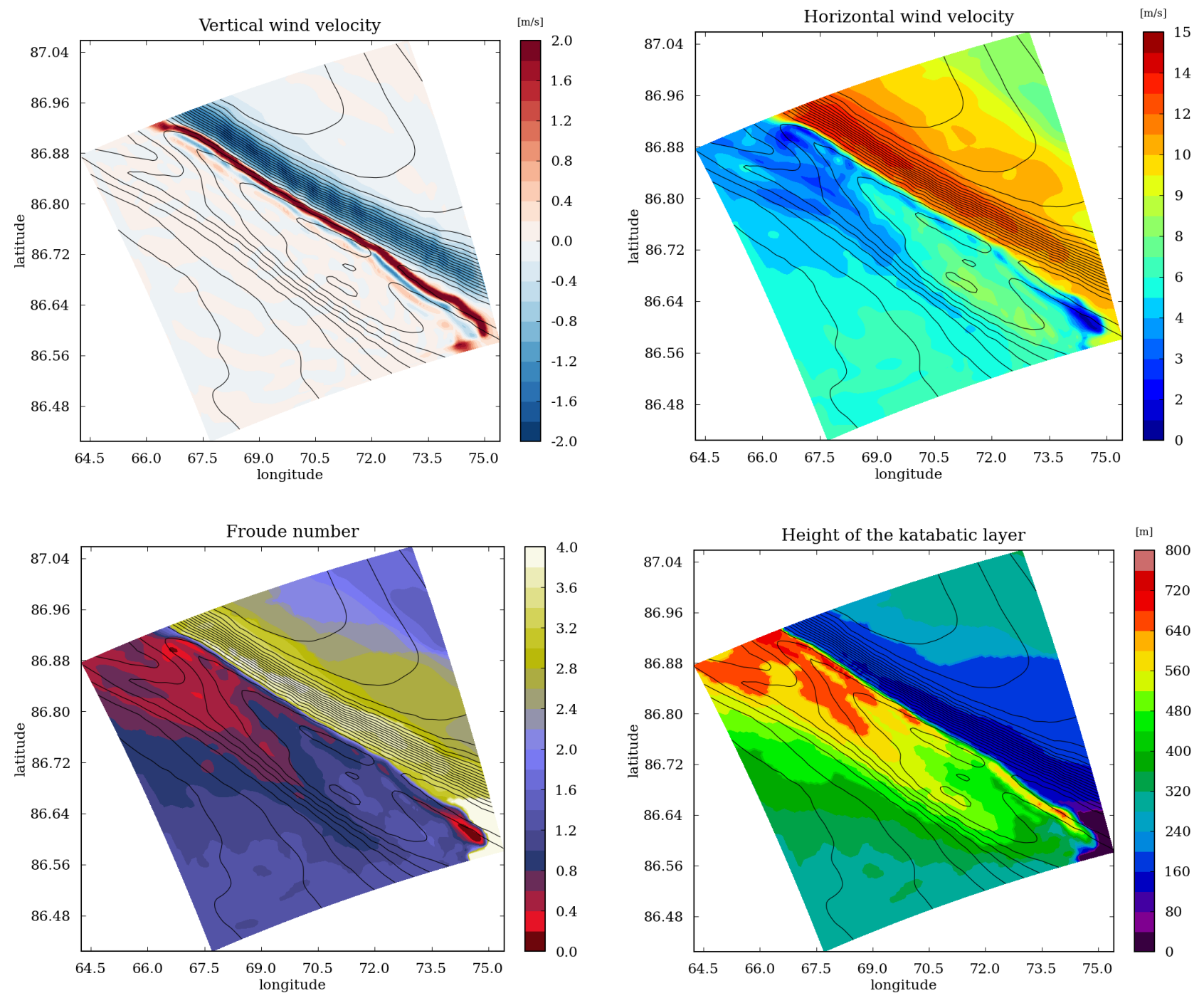

Figure 7: LMD-MMM results in nested domain \#5 $(\Delta x=250 \mathrm{~m})$ at local time 1730 on the second day of simulation. Horizontal maps of vertical wind velocity (top-left panel), horizontal wind velocity (top-right panel), Froude number Fr (bottom-left panel), and height of katabatic layer $h$ (bottom-right panel). The first two quantities are shown at a constant altitude of $130 \mathrm{~m}$ above the surface; details on computations of the last two quantities $h$ and $F r$ are provided in the text. Topography is superimposed as contours (see Figure 3, bottom-right panel). North is to the upper part of the plot; katabatic flow is coming from the upper right and accelerate downward perpendicular to the trough. The periodic features seen in the vertical velocity field over the steepest slope of the trough are caused by small artefacts in the MOLA topographical datasets used for our mesoscale simulations. This does not adversely affect the results in this paper. 

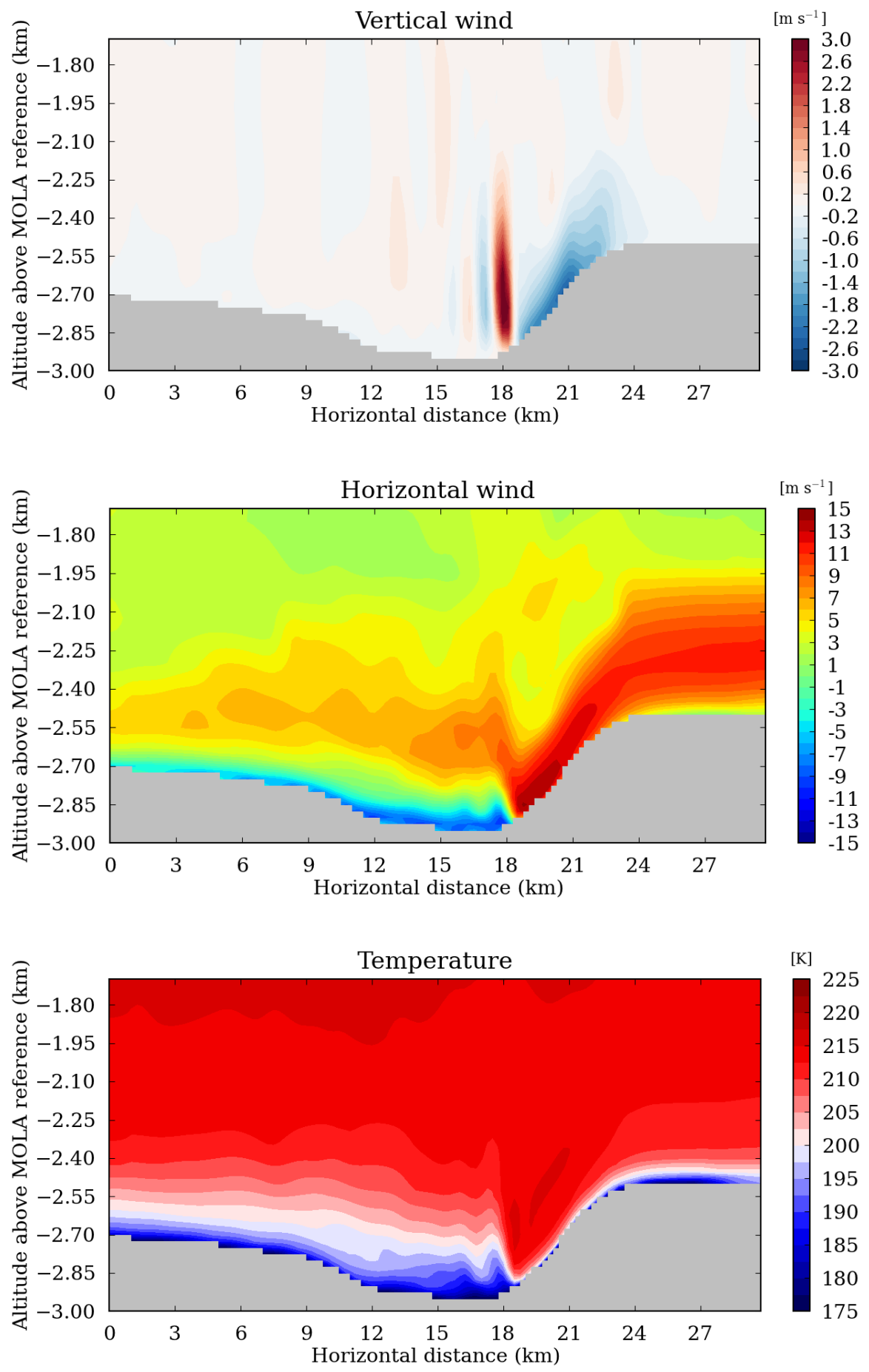

Figure 8: $\quad L M D-M M M$ results in nested domain \#5 $(\Delta x=250 \mathrm{~m})$. Horizontal-vertical crosssection of vertical wind velocity (top), horizontal wind velocity (middle), temperature (K). Horizontal dimension is along the south-north direction (north is on the rightside). Horizontal wind is positive in the southward direction (i.e. downstream, following the katabatic flow incoming on a polar trough). Regular temperature is shown in this figure, in contrast with Figure 6 where potential temperature is shown. 

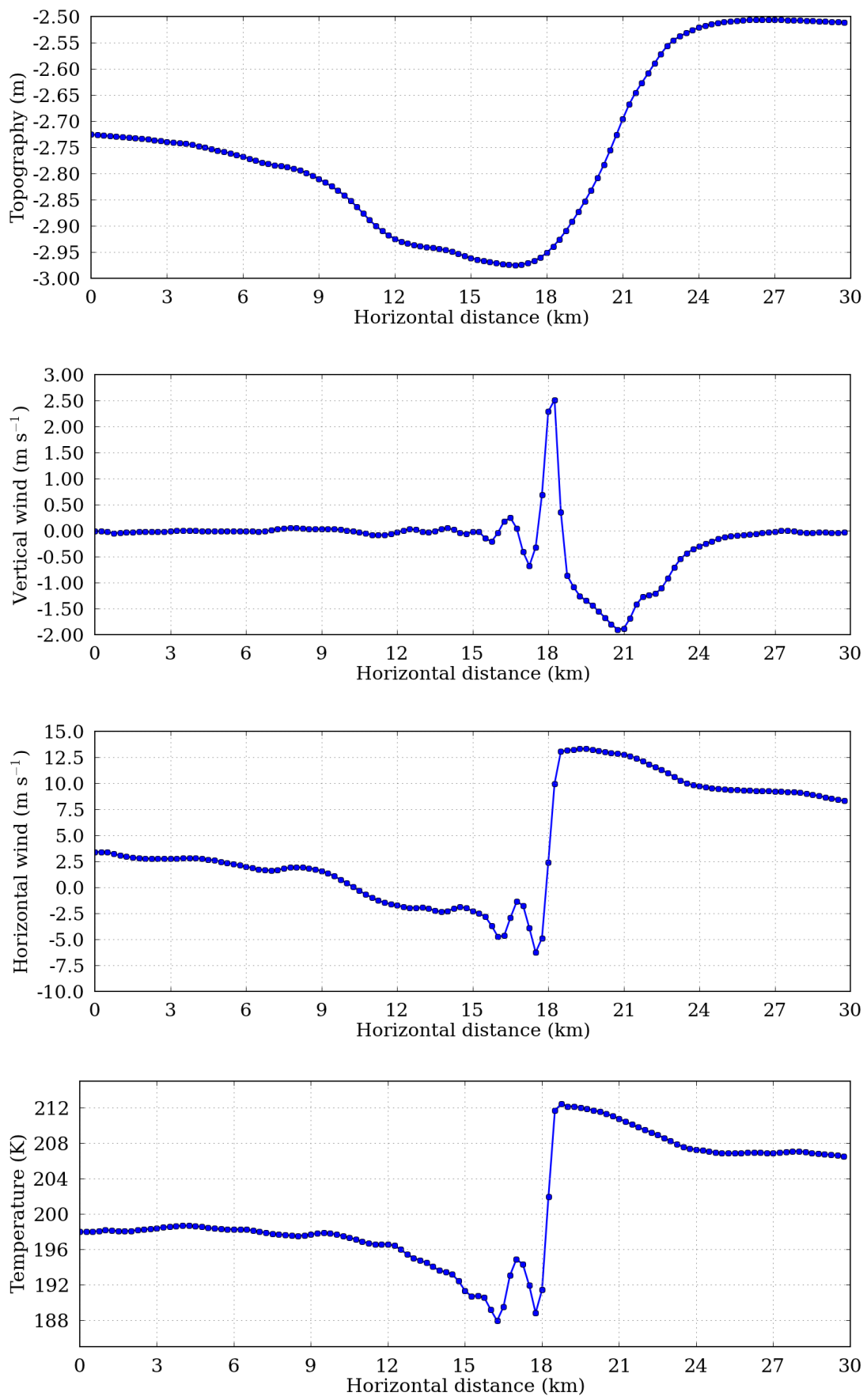

Figure 9: LMD-MMM results in nested domain \#5 $(\Delta x=250 \mathrm{~m})$. From top to bottom: topography, vertical wind velocity, horizontal wind velocity, (regular) temperature. Those fields are shown at the constant altitude of $100 \mathrm{~m}$ above the local surface. Horizontal dimension is along the south-north direction, with north on the rightside, as in Figure 8. Horizontal wind is positive in the southward (downstream) direction. 
by a sea-breeze effect caused by thermal gradients associated with the "crocus line" (the contrast between the retreating seasonal $\mathrm{CO}_{2}$ ice cap and the residual surface - bare soil or water-ice cap). The location of the trough chosen as a target for our domain \#5 is in the vicinity of the crocus line at $L_{s} \sim 85^{\circ}$. Furthermore, the intensity of katabatic jumps is sensitive to meteorological conditions around $L_{s} \sim 85^{\circ}$, following the modulation of the polar cap's katabatic flow by diurnal and dayto-day variability (through baroclinic wave activity or polar transients). Over the course of our 3-day mesoscale simulation, two additional katabatic jump events analogous to the reference event detailed in Figures 7, 8, 9 are produced (Figure 10), although their amplitude is lower $\left(1 \mathrm{~m} \mathrm{~s}^{-1}\right.$ instead of $3 \mathrm{~m} \mathrm{~s}^{-1}$ in vertical velocity) and undulations do not appear as clearly as in the reference event. We found that the variations of the incoming katabatic wind in the considered polar trough in Figure 10 is caused by transient eddies with dominant wavenumber 1, akin to the phenomena described in Tyler and Barnes (2005) later in northern summer. A more complete analysis of the diversity of katabatic jumps occurring over the northern polar cap as a result of polar transients will require longer-duration mesoscale simulations as in Tyler and Barnes (2005).

As is mentioned above, the katabatic jump is associated with a sudden drop in the horizontal wind speed (Figure 7, top-right panel; Figure 9, middle panel), i.e. an abrupt drop of velocity within an otherwise smooth katabatic flow that continues almost uninterrupted downstream of the polar trough. Figure 6 and Figure 8 (middle panel) show that the horizontal wind in the vicinity of the katabatic jump is even reversing to upstream direction (with respect to the incoming katabatic flow) with a significant wind velocity of $\sim 10 \mathrm{~m} \mathrm{~s}^{-1}$. As it is the case with polar katabatic jumps on the Earth, the area immediately downstream of the katabatic jump is prone to enhanced mixing and/or stationary flow, which is compliant with the cloud structures observed from orbit in those areas (see Figure 1 in this paper and Figures 3-5, 7-8, 11 in Smith et al., 2013).

Katabatic jumps borrow their name from their similarity to hydraulic jumps in open channel flow, which form as the flow transitions from a supercritical "shooting" regime with $\mathrm{Fr}>1$ to a subcritical "tranquil" regime with $F r<1($ Ball, 1956), where $F r$ is the Froude number which can 

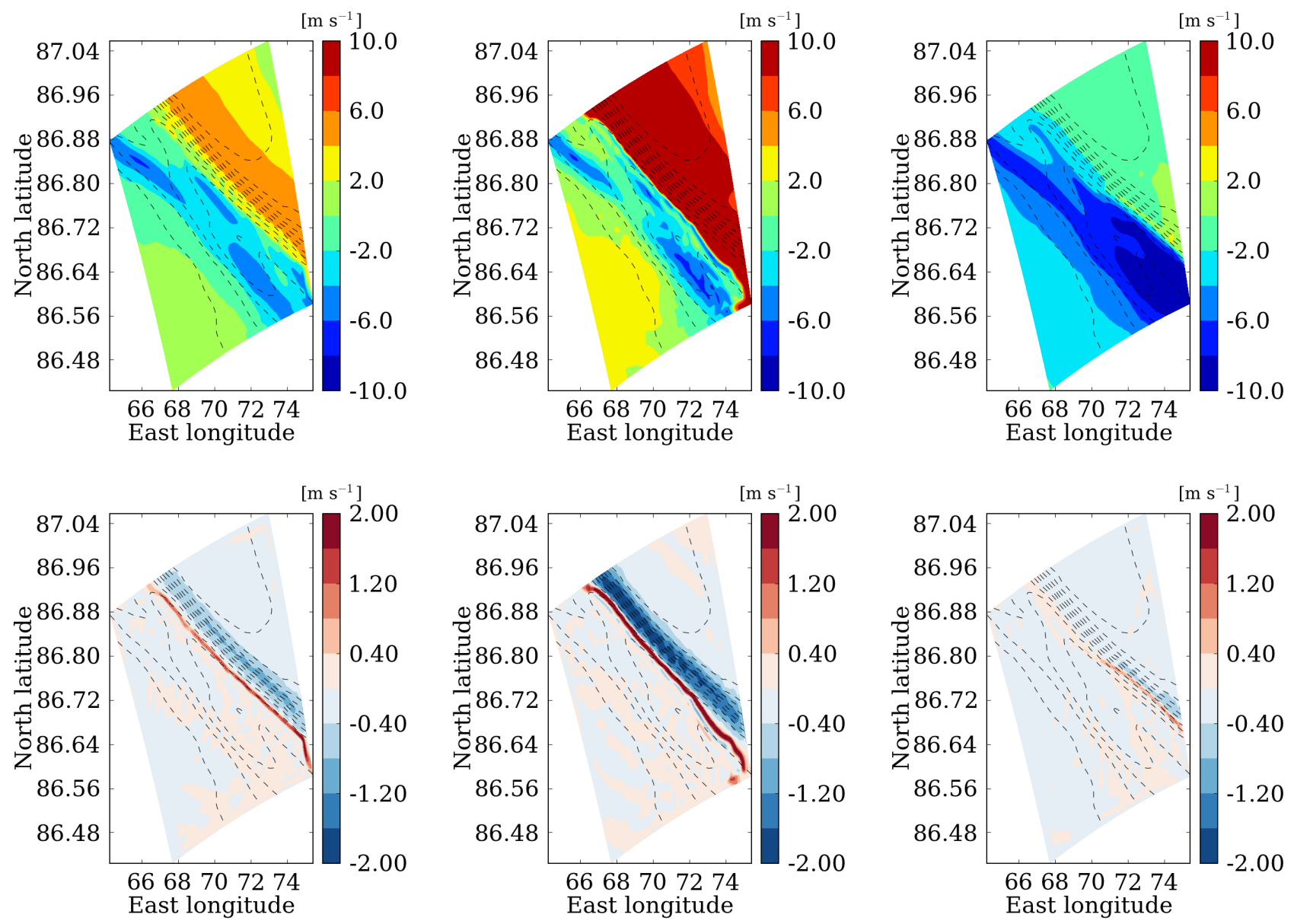

Figure 10: $L M D-M M M$ results in nested domain $\# 5(\Delta x=250 \mathrm{~m})$ at local time 1730 on the first, second and third day of simulation (respectively left, middle, right panels). Horizontal maps of south-north horizontal wind (top panels, with positive values for downstream direction) and vertical wind velocity (bottom panels). Topography is superimposed as contours. Middle row shows the reference katabatic jump event detailed in Figure 7 .

292 be expressed after Pettré and André (1991)

$$
F r=\frac{u}{\sqrt{\frac{\Delta \theta}{\theta} g h}}
$$

293 where $u$ is the along-slope wind speed, $\Delta \theta / \theta$ the near-surface inversion of potential temperature, $294 g$ is the acceleration of gravity, and $h$ is the thickness of the katabatic layer (as is defined above 
and in Figure 7 bottom-right panel). We mapped the Froude number in domain \#5 in Figure 7 (bottom-left panel). The katabatic flow is highly supercritical $(F r>2$ with peak values close to 4.5) over the upstream slope, where the katabatic wind speed is larger and the katabatic layer is thinner (two essential factors to obtain a supercritical flow), and this flow undergoes an abrupt transition to subcritical values $(F r=0.2-0.4)$ at the bottom of the slope. The katabatic jump is found where the incoming flow transitions from a supercritical to a subcritical regime. This is compliant with the katabatic jumps occurring close to the slope break between the upstream trough slope and the downstream trough bottom (Figures 8 and 9), which is also where trough clouds are observed (Smith et al., 2013).

The acceleration of the katabatic wind in the upstream slope of the trough pertains to a larger class of atmospheric phenomena named "downslope windstorms" (Durran, 1990; Magalhāes and Young, 1995). This phenomena occurs for instance on the leeside of a mountain when an incident large-scale wind flow vanishes to zero near the surface and encounters a non-linear boundary condition (Lott, 2016). Furthermore, strong downslope winds are especially favored in stable conditions. Convective instability at low level in the mountain leeside might occur with a hydraulicjump-like morphology. Both the downslope windstorm and the hydraulic jump do not require gravity wave breaking to form. Downslope windstorms with similar properties were shown to arise as a result of a katabatic flow impinging on the Meteor Crater topographic depression on the Earth, with hydraulic jumps arising shall the background wind be strong enough and the crater be deep enough (Lehner et al., 2016). The katabatic jumps in polar troughs bear a strong resemblance with this terrestrial analog. Besides, this terrestrial example suggests that katabatic jumps shall occur downstream of the rims of a deep-enough crater on Mars on which a strongenough regional-scale katabatic flow is impinging - such as, for instance, within Gale Crater located at the dichotomy boundary (Haberle et al., 2014, Pla-Garcia et al., 2016, Rafkin et al., 2016). Hydraulic jumps generated by katabatic winds were also thought to cause the early morning elongated clouds observed by the Viking Orbiters during late northern spring and early summer 
(Kahn and Gierasch, 1982); mesoscale modeling provided, however, an explanation based on the propagation of an atmospheric bore wave generated by a katabatic front (Sta. Maria et al., 2006), which would be the propagating equivalent of the nearly-stationary katabatic jump we model here.

An important point to discuss ice migration in Martian polar troughs is to know whether the downslope windstorm and the katabatic jump are conducive to the formation of trough clouds as hypothesized in Smith et al. (2013). Katabatic jumps in terrestrial polar regions often lead to the formation of clouds named "wall-of-snow" (Pettré and André, 1991), and the visual appearance of elongated trough clouds on Mars (Figure 1) is reminiscent of those terrestrial clouds. The temperature simulated in the polar trough is shown in Figure 8 and 9 (bottom panels). Within the katabatic flow blowing downslope the trough, atmospheric temperatures are strongly increasing under the influence of adiabatic compression (Spiga et al., 2011) to reach $210 \mathrm{~K}$; when the katabatic flow undergoes the katabatic jump, atmospheric temperatures are abruptly decreasing to $190 \mathrm{~K}$. Both conditions are highly propitious to the formation of water-ice clouds at the location of the katabatic jump: not only the downslope windstorm implies enhanced sublimation of ground ice to the atmosphere (by enhanced sensible heat flux), but this water-vapor-rich katabatic flow quickly encounters a drop in saturation vapor pressure caused by the $-20 \mathrm{~K}$ drop in atmospheric temperature associated with the katabatic jump. Water ice at the surface is available for sublimation at $L_{s}=85^{\circ}$ in the trough modeled here; the presence of $\mathrm{CO}_{2}$ ice at other seasons, and the seasonal variability of the surface temperature of water-ice deposits, could yield a much less favorable case for sublimation over the northern polar cap, thereby accounting for the strong seasonality of trough clouds (cf. companion paper Smith and Spiga (2017)).

․ Using Clausius-Clapeyron equations for the Martian atmospheric conditions (e.g., Montmessin et al. 2004), we compute the saturation mass mixing ratio $q_{\text {sat }}$ for the pressure and temperature conditions simulated by our model (cf. Figure 8). We then obtain specific humidity $H=q / q_{\text {sat }}$, where $q$ is a typical near-surface mass mixing ratio for water vapor in the summertime northern polar regions, $3 \times 10^{-4} \mathrm{~kg} / \mathrm{kg}$ according to LMD-MGCM simulations compiled in the Mars Climate 


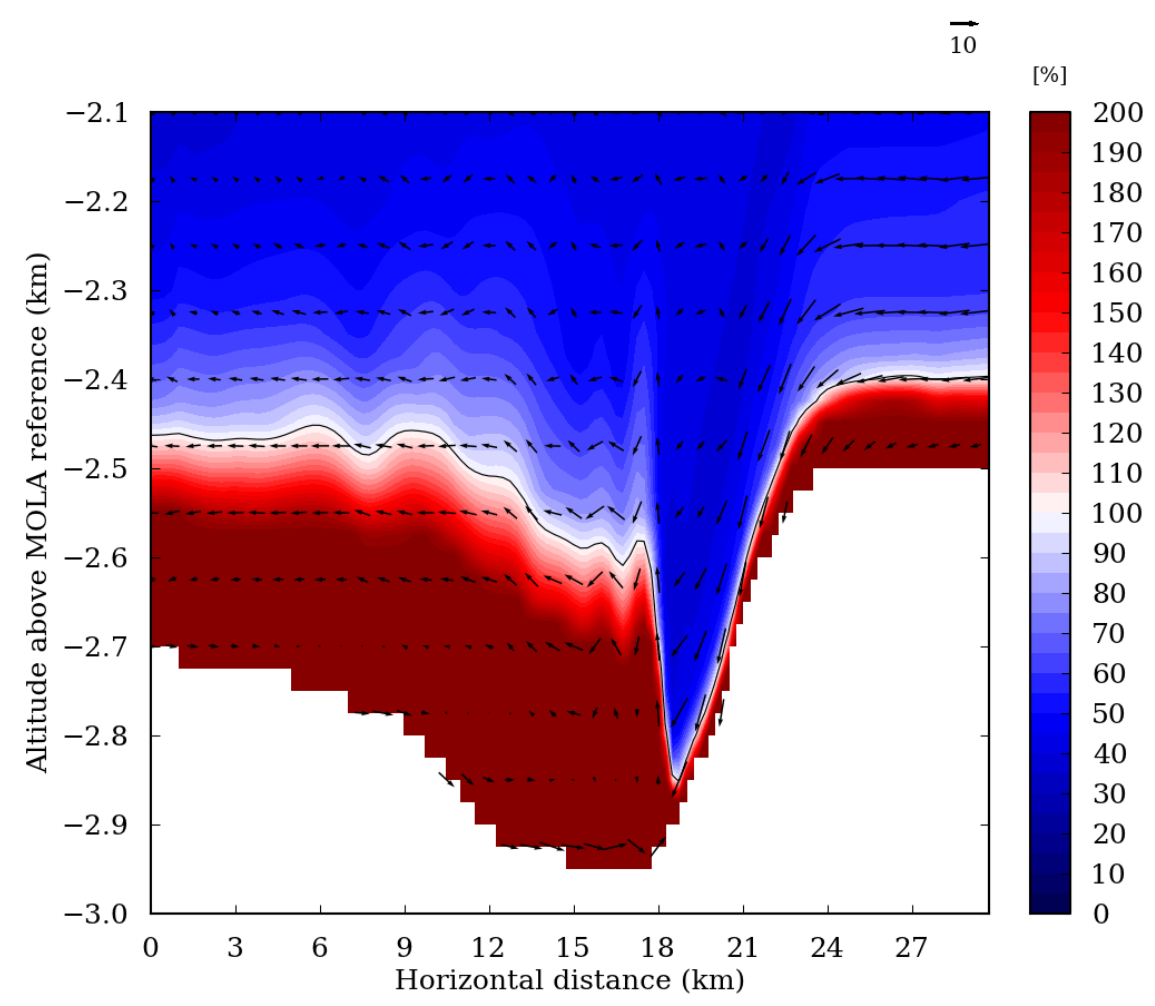

Figure 11: LMD-MMM results in nested domain \#5 $(\Delta x=250 \mathrm{~m})$. Horizontal-vertical crosssection of specific humidity (see text for details on calculations) with wind vectors superimposed (the reference wind vector with a value in $\mathrm{m} \mathrm{s}^{-1}$ is included in the top right side of the plot). The $100 \%$ humidity limit is indicated by a solid line. Vectors are plotted every three grid points. This cross-section in the south-north direction (north is on the rightside) is extracted in the middle of domain \#5 in the west-east direction.

Database (Lewis et al., 1999, Millour et al., 2015). This quantity $H$ is shown in Figure 11. which strongly suggests that the incoming katabatic flow undergoes subsaturated conditions when entering the polar trough, as a result of adiabatic warming, before it undergoes supersaturated conditions at the katabatic jump, conducive to the formation of water-ice clouds. The fact that in Figure 11 the strongest horizontal gradient of specific humidity coincides with the location of the katabatic jump means that the water-ice cloud forms very close to this katabatic jump. This explains that the horizontal elongated morphology of this jump (Figure 7) matches the morphology 
of the observed trough clouds (Smith et al., 2013). Our modeling is thus in line with the putative scenario described in Smith et al. (2013) for ice migration within polar troughs, with the upstream slope of the trough being ablational for ice deposits (through enhanced sublimation and transport away from the source) and the downstream bottom of the trough being depositional for ice deposits (through water-ice cloud formation). It remains to be determined with a full microphysical model (e.g., Navarro et al., 2014; Spiga et al., 2017) whether the cloud formation implies deposition of ice on the ground by precipitation (if the cloud does not form immediately above the surface) or by direct deposition (if the cloud forms right above the local surface, or if transported water vapor directly recondenses at the surface).

\section{Discussion}

Our conclusions can be summarized as follows.

1. We demonstrate through high-resolution nested mesoscale modeling that powerful katabatic jumps occur within the northern polar troughs with an incoming downslope (katabatic) windstorm.

2. The katabatic jumps occur while the incoming flow transitions from supercritical shooting conditions on the upstream slope of the trough to subcritical tranquil conditions in the downstream part of the trough, making katabatic jumps analogous to hydraulic jumps in open channel flows.

3. Those Martian phenomena are strikingly similar to the Loewe phoenomena described in terrestrial polar regions (Pettré and André, 1991).

4. The combination of the downslope windstorms and katabatic jumps make the Martian atmospheric conditions in polar troughs propitious to the formation of water-ice clouds which morphology is similar to the observed trough clouds. 
Our conclusions strengthen the scenario hypothesized by Smith et al. (2013): trough clouds are the visible manifestation of katabatic jumps, which might support a mechanism for ice migration over geological through cyclic steps (Kostic et al., 2010), thereby providing an explanation for the stratigraphy revealed by orbital radar measurements. Despite our new conclusions obtained through unprecedented mesoscale modeling, further work is needed to describe the definitive scenario about ice migration over the Martian northern polar caps.

- Mesoscale modeling coupled to water vapor transport and water ice microphysics is needed to understand how deposition of water ice on the surface occurs from precipitation or direct deposition from trough clouds.

- The seasonal and spatial variability of trough clouds needs to be assessed with more extensive simulations accounting for the combined influence of katabatic acceleration, baroclinic waves and polar transients.

- The stability and possible migration over geological timescales of water ice surface reservoirs in the Martian polar regions is left to be investigated by paleoclimatic mesoscale modeling; the influence of the varying obliquity is probably an important element to future studies.

- It remains to be elucidated how troughs are initiated on the polar cap surface, and how possible katabatic jumps occurring without an initial slope break could form initial surface erosional features that could be reinforced through time to form polar troughs.

On a broader perspective, the present work emphasizes how surface-atmosphere interactions are key to understand the properties and evolution of the polar regions of Mars. Additional observations obtained by a dedicated polar orbiter or lander would allow for an in-depth validation of the scenario built here upon numerical modeling. 


\section{Acknowledgments}

We thank François Lott for helpful suggestions on mesoscale atmospheric dynamics, Jack Holt for discussions on Martian polar processes, and Dan Tyler for discussions on atmospheric processes in Martian polar regions. Isaac Smith acknowledges funding from the Fulbright Commission during a scientific visit at LMD (Paris) in 2014, which initiated this study. Aymeric Spiga acknowledges funding from Centre National d'Études Spatiales (CNES). We thank two reviewers for constructive and thorough comments which helped us to improve the manuscript prior to publication.

\section{References}

Appéré, T., Schmitt, B., Langevin, Y., Douté, S., Pommerol, A., Forget, F., Spiga, A., Gondet, B., and Bibring, J.-P. (2011). Winter and spring evolution of northern seasonal deposits on Mars from OMEGA on Mars Express. Journal of Geophysical Research (Planets), 116(E15):5001.

Ball, F. (1956). The Theory of Strong Katabatic Winds. Australian Journal of Physics, 9:373.

Barnes, J. R., Pollack, J. B., Haberle, R. M., Zurek, R. W., Leovy, C. B., Lee, H., and Schaeffer, J. (1993). Mars atmospheric dynamics as simulated by the NASA/Ames general circulation model, 2, Transient baroclinic eddies. J. Geophys. Res., 98(E2):3125-3148.

Bromwich, D. H., Cassano, J. J., Klein, T., Heinemann, G., Hines, K. M., Steffen, K., and Box, J. E. (2001). Mesoscale Modeling of Katabatic Winds over Greenland with the Polar MM5. Monthly Weather Review, 129:2290-2309.

Brothers, T. C., Holt, J. W., and Spiga, A. (2013). Orbital radar, imagery, and atmospheric modeling reveal an aeolian origin for Abalos Mensa, Mars. Geophysical Research Letters, 40:1334-1339.

Cantor, B., Malin, M., and Edgett, K. S. (2002). Multiyear Mars Orbiter Camera (MOC) obser- 
vations of repeated Martian weather phenomena during the northern summer season. Journal of Geophysical Research (Planets), 107:5014-+.

Colaïtis, A., Spiga, A., Hourdin, F., Rio, C., Forget, F., and Millour, E. (2013). A thermal plume model for the Martian convective boundary layer. Journal of Geophysical Research (Planets), 118:1468-1487.

Collins, M., Lewis, S. R., Read, P. L., and Hourdin, F. (1996). Baroclinic wave transitions in the Martian atmosphere. Icarus, 120:344-357.

Durran, D. R. (1990). Mountain Waves and Downslope Winds, pages 59-81. American Meteorological Society, Boston, MA.

Forget, F., Hourdin, F., Fournier, R., Hourdin, C., Talagrand, O., Collins, M., Lewis, S. R., Read, P. L., and Huot., J.-P. (1999). Improved general circulation models of the Martian atmosphere from the surface to above $80 \mathrm{~km}$. J. Geophys. Res., 104:24,155-24,176.

Gallée, H. and Schayes, G. (1992). Dynamical aspects of katabatic wind evolution in the antarctic coastal zone. Boundary-Layer Meteorology, 59(1):141-161.

Gallée, H., Pettré, P., and Schayes, G. (1996). Sudden cessation of katabatic winds in adélie land, antarctica. Journal of Applied Meteorology, 35(7):1142-1152.

Galperin, B. A., Kantha, L. H., Hassid, S., and Rosati, A. (1988). A quasi-equilibrium turbulent energy model for geophysical flows. J. Atmos. Sci., 45:55-62.

Guzewich, S. D., Toigo, A. D., and Waugh, D. W. (2016). The effect of dust on the martian polar vortices. Icarus, 278:100-118.

Haberle, R. M., Gómez-Elvira, J., Torre Juárez, M., Harri, A.-M., Hollingsworth, J. L., Kahanpää, H., Kahre, M. A., Lemmon, M., Martín-Torres, F. J., Mischna, M., Moores, J. E., Newman, C., Rafkin, S. C. R., Rennó, N., Richardson, M. I., Rodríguez-Manfredi, J. A., Vasavada, A. R., 
and Zorzano-Mier, M.-P. (2014). Preliminary interpretation of the REMS pressure data from the first 100 sols of the MSL mission. Journal of Geophysical Research (Planets), 119:440-453.

Herny, C., Massé, M., Bourgeois, O., Carpy, S., Le Mouélic, S., Appéré, T., Smith, I. B., Spiga, A., and Rodriguez, S. (2014). Sedimentation waves on the Martian North Polar Cap: Analogy with megadunes in Antarctica. Earth and Planetary Science Letters, 403:56-66.

Holt, J. W., Fishbaugh, K. E., Byrne, S., Christian, S., Tanaka, K., Russell, P. S., Herkenhoff, K. E., Safaeinili, A., Putzig, N. E., and Phillips, R. J. (2010). The construction of Chasma Boreale on Mars. Nature, 465:446-449.

Holton, J. R. (2004). An introduction to dynamic meteorology, volume 48 of International geophysics series. Elsevier Academic Press, fourth edition.

Howard, A. D. (2000). The Role of Eolian Processes in Forming Surface Features of the Martian Polar Layered Deposits. Icarus, 144:267-288.

Howard, A. D., Cutts, J. A., and Blasius, K. R. (1982). Stratigraphic relationships within Martian polar CAP deposits. Icarus, 50:161-215.

Kahn, R. and Gierasch, P. (1982). Long clouds observations on Mars and implications for boundary layer characteristics over slopes. J. Geophys. Res., 87:867-880.

Kauhanen, J., Siili, T., Järvenoja, S., and Savijärvi, H. (2008). The Mars limited area model and simulations of atmospheric circulations for the Phoenix landing area and season of operation. Journal of Geophysical Research (Planets), 113:E00A14.

Kieffer, H. H., Titus, T. N., Mullins, K. F., and Christensen, P. R. (2000). Mars south polar spring and summer behavior observed by TES: Seasonal cap evolution controlled by frost grain size. J. Geophys. Res., 105:9653-9700. 
Kostic, S., Sequeiros, O., Spinewine, B., and Parker, G. (2010). Cyclic steps: A phenomenon of supercritical shallow flow from the high mountains to the bottom of the ocean. Journal of Hydro-environment Research, 3(4):167-172.

Lehner, M., Rotunno, R., and Whiteman, C. D. (2016). Flow regimes over a basin induced by upstream katabatic flows - an idealized modeling study. Journal of the Atmospheric Sciences, $73: 3821-3842$.

Lewis, S. R., Collins, M., Read, P. L., Forget, F., Hourdin, F., Fournier, R., Hourdin, C., Talagrand, O., and Huot., J.-P. (1999). A climate database for Mars. J. Geophys. Res., 104:24,177-24,194.

Lied, N. T. (1964). Stationary hydraulic jumps in a katabatic flow near davis, antarctica, 1961. Aust. Meteorol. Mag, 47:40-51.

Lott, F. (2016). A new theory for downslope windstorms and trapped mountain waves. Journal of the Atmospheric Sciences, 73(9):3585-3597.

Madeleine, J.-B., Forget, F., Millour, E., Navarro, T., and Spiga, A. (2012). The influence of radiatively active water ice clouds on the Martian climate. Geophys. Res. Lett., 39:23202.

Magalhāes, J. A. and Young, R. E. (1995). Downslope Windstorms in the Lee of Ridges on Mars. Icarus, 113:277-294.

Mahrt, L. (1982). Momentum Balance of Gravity Flows. Journal of the Atmospheric Sciences, 39(12):2701-2711.

Massé, M., Bourgeois, O., Le Mouélic, S., Verpoorter, C., Spiga, A., and Le Deit, L. (2012). Wide distribution and glacial origin of polar gypsum on Mars. Earth and Planetary Science Letters, $317: 44-55$

McCleese, D. J., Schofield, J. T., Taylor, F. W., Abdou, W. A., Aharonson, O., Banfield, D., Calcutt, S. B., Heavens, N. G., Irwin, P. G. J., Kass, D. M., Kleinböhl, A., Lawson, W. G., 
Leovy, C. B., Lewis, S. R., Paige, D. A., Read, P. L., Richardson, M. I., Teanby, N., and Zurek, R. W. (2008). Intense polar temperature inversion in the middle atmosphere on Mars. Nature Geoscience, 1:745-749.

Mellor, G. L. and Yamada, T. (1982). Development of a turbulence closure model for geophysical fluid problems. Rev. of Geophys., 20(4):851-875.

Michaels, T. I. and Rafkin, S. C. R. (2004). Large eddy simulation of atmospheric convection on Mars. Q. J. R. Meteorol. Soc., 130:1251-1274.

Michaels, T. I. and Rafkin, S. C. R. (2008). Meteorological predictions for candidate 2007 Phoenix Mars Lander sites using the Mars Regional Atmospheric Modeling System (MRAMS). Journal of Geophysical Research (Planets), 113(E12):0-+.

Millour, E., Forget, F., Spiga, A., Navarro, T., Madeleine, J.-B., Montabone, L., Pottier, A., Lefevre, F., Montmessin, F., Chaufray, J.-Y., Lopez-Valverde, M. A., Gonzalez-Galindo, F., Lewis, S. R., Read, P. L., Huot, J.-P., Desjean, M.-C., and MCD/GCM development Team (2015). The Mars Climate Database (MCD version 5.2). European Planetary Science Congress 2015, 10:EPSC2015-438.

Mitchell, D. M., Montabone, L., Thomson, S., and Read, P. L. (2015). Polar vortices on Earth and Mars: A comparative study of the climatology and variability from reanalyses. Quarterly Journal of the Royal Meteorological Society, 141:550-562.

Montabone, L., Forget, F., Millour, E., Wilson, R. J., Lewis, S. R., Cantor, B., Kass, D., Kleinböhl, A., Lemmon, M. T., Smith, M. D., and Wolff, M. J. (2015). Eight-year climatology of dust optical depth on Mars. Icarus, 251:65-95.

Montmessin, F., Forget, F., Rannou, P., Cabane, M., and Haberle, R. M. (2004). Origin and role of water ice clouds in the Martian water cycle as inferred from a general circulation model. Journal of Geophysical Research (Planets), 109(E18):10004. 
Navarro, T., Madeleine, J.-B., Forget, F., Spiga, A., Millour, E., Montmessin, F., and Määttänen, A. (2014). Global Climate Modeling of the Martian water cycle with improved microphysics and radiatively active water ice clouds. Journal of Geophysical Research (Planets).

Nylen, T. H., Fountain, A. G., and Doran, P. T. (2004). Climatology of katabatic winds in the McMurdo dry valleys, southern Victoria Land, Antarctica. Journal of Geophysical Research (Atmospheres), 109:D03114.

Parish, T. R. and Waight, K. T. (1987). The Forcing of Antarctic Katabatic Winds. Monthly Weather Review, 115:2214-+.

Pathare, A. V. and Paige, D. A. (2005). The effects of martian orbital variations upon the sublimation and relaxation of north polar troughs and scarps. Icarus, 174:419-443.

Pettré, P. and André, J.-C. (1991). Surface-Pressure Change through Loewe's Phenomena and Katabatic Flow Jumps: Study of Two Cases in Adélie Land, Antarctica. Journal of Atmospheric Sciences, 48:557-571.

Pettré, P., Payan, C., and Parish, T. R. (1993). Interaction of katabatic flow with local thermal effects in a coastal region of adelie land, east antarctica. Journal of Geophysical Research: Atmospheres, 98(D6):10429-10440.

Pla-Garcia, J., Rafkin, S. C. R., Kahre, M., Gomez-Elvira, J., Hamilton, V. E., Navarro, S., Torres, J., Marín, M., and Vasavada, A. R. (2016). The meteorology of Gale crater as determined from rover environmental monitoring station observations and numerical modeling. Part I: Comparison of model simulations with observations. Icarus, 280:103-113.

Rafkin, S. C. R., Haberle, R. M., and Michaels, T. I. (2001). The Mars Regional Atmospheric Modeling System: Model Description and Selected Simulations. Icarus, 151:228-256. 
Rafkin, S. C. R., Pla-Garcia, J., Kahre, M., Gomez-Elvira, J., Hamilton, V. E., Marín, M., Navarro, S., Torres, J., and Vasavada, A. (2016). The meteorology of Gale Crater as determined from Rover Environmental Monitoring Station observations and numerical modeling. Part II: Interpretation. Icarus, 280:114-138.

Siili, T., Haberle, R. M., Murphy, J. R., and Savijarvi, H. (1999). Modelling of the combined late-winter ice cap edge and slope winds in Mars Hellas and Argyre regions. Planet. Space Sci., 47:951-970.

Skamarock, W. C. and Klemp, J. B. (2008). A time-split nonhydrostatic atmospheric model for weather research and forecasting applications. Journal of Computational Physics, 227:34653485.

Smagorinsky, J. (1963). General circulation experiments with the primitive equations. i. the basic experiment. Mon. Weather Rev., 91:99-164.

Smith, D. E., Zuber, M. T., Frey, H. V., Garvin, J. B., Head, J. W., Muhleman, D. O., Pettengill, G. H., Phillips, R. J., Solomon, S. C., Zwally, H. J., Banerdt, W. B., Duxbury, T. C., Golombek, M. P., Lemoine, F. G., Neumann, G. A., Rowlands, D. D., Aharonson, O., Ford, P. G., Ivanov, A. B., Johnson, C. L., McGovern, P. J., Abshire, J. B., Afzal, R. S., and Sun, X. (2001). Mars Orbiter Laser Altimeter: Experiment summary after the first year of global mapping of Mars. J. Geophys. Res., 106:23689-23722.

Smith, I. and Spiga, A. (2017). Seasonal Variability in Winds in the North Polar Region of Mars. Icarus (revision submitted).

Smith, I. B. and Holt, J. W. (2010). Onset and migration of spiral troughs on Mars revealed by orbital radar. Nature, 465:450-453.

Smith, I. B. and Holt, J. W. (2015). Spiral trough diversity on the north pole of mars, as seen by shallow radar (sharad). Journal of Geophysical Research: Planets, 120(3):362-387. 
Smith, I. B., Holt, J. W., Spiga, A., Howard, A. D., and Parker, G. (2013). The spiral troughs of mars as cyclic steps. Journal of Geophysical Research: Planets, 118(9):1835-1857.

Smith, I. B., Spiga, A., and Holt, J. W. (2015). Aeolian processes as drivers of landform evolution at the South Pole of Mars. Geomorphology, 240:54-69.

Spiga, A. (2011). Elements of comparison between Martian and terrestrial mesoscale meteorological phenomena: Katabatic winds and boundary layer convection. Planetary and Space Science, 59:915-922.

Spiga, A., Faure, J., Madeleine, J.-B., Määttänen, A., and Forget, F. (2013). Rocket dust storms and detached dust layers in the Martian atmosphere. Journal of Geophysical Research (Planets), 118:746-767.

Spiga, A. and Forget, F. (2009). A new model to simulate the Martian mesoscale and microscale atmospheric circulation: Validation and first results. Journal of Geophysical Research (Planets), 114:E02009.

Spiga, A., Forget, F., Lewis, S. R., and Hinson, D. P. (2010). Structure and dynamics of the convective boundary layer on mars as inferred from large-eddy simulations and remote-sensing measurements. Quarterly Journal of the Royal Meteorological Society, 136:414-428.

Spiga, A., Forget, F., Madeleine, J., Montabone, L., Lewis, S. R., and Millour, E. (2011). The impact of Martian mesoscale winds on surface temperature and on the determination of thermal inertia. Icarus, 212:504-519.

Spiga, A., Hinson, D., Madeleine, J., Navarro, T., Millour, E., Forget, F., and Montmessin, F. (2017). Snow precipitation on Mars driven by cloud-induced nighttime convection. Nature Geoscience, 10:652-657. 
Sta. Maria, M. R. V., Rafkin, S. C. R., and Michaels, T. I. (2006). Numerical simulation of atmospheric bore waves on Mars. Icarus, 185:383-394.

Titus, T. N. (2005). Mars Polar Cap Edges Tracked over 3 Full Mars Years. In Mackwell, S. and Stansbery, E., editors, 36th Annual Lunar and Planetary Science Conference, volume 36 of Lunar and Planetary Inst. Technical Report.

Toigo, A. D., Lee, C., Newman, C. E., and Richardson, M. I. (2012). The impact of resolution on the dynamics of the martian global atmosphere: Varying resolution studies with the MarsWRF GCM. Icarus, 221:276-288.

Toigo, A. D., Richardson, M. I., Wilson, R. J., Wang, H., and Ingersoll, A. P. (2002). A first look at dust lifting and dust storms near the south pole of Mars with a mesoscale model. Journal of Geophysical Research (Planets), 107:5050-+.

Tyler, D. and Barnes, J. R. (2005). A mesoscale model study of summertime atmospheric circulations in the north polar region of Mars. Journal of Geophysical Research (Planets), 110(E9):6007+ .

Tyler, D. and Barnes, J. R. (2014). Atmospheric mesoscale modeling of water and clouds during northern summer on Mars. Icarus, 237:388-414.

Tyler, D., Barnes, J. R., and Skyllingstad, E. D. (2008). Mesoscale and large-eddy simulation model studies of the Martian atmosphere in support of Phoenix. Journal of Geophysical Research (Planets), 113(E12):0-+.

Wilson, R. J. (1997). A general circulation model of the Martian polar warming. Geophys. Res. Lett., 24:123-126.

Wyngaard, J. (2004). Toward Numerical Modeling in the iTerra Incognitaj. Journal of the Atmospheric Sciences, 61(14):1816-1826. 
${ }_{603} \mathrm{Yu}, \mathrm{Y}$. and Cai, X.-M. (2006). Structure and dynamics of katabatic flow jumps: idealised simulations. Boundary-layer meteorology, 118(3):527-555. 